\title{
A Study on Students' Use of Punctuation Marks in English Writing - A Case Study of Nepal
}

\author{
Ramesh Prasad Adhikary \\ Tribhuwan University, Kathmandu, M.M. Campus, Nepalgunj, Nepal \\ Email: rameshadhikary29@gmail.com
}

\begin{abstract}
The present research is focused on correct and erroneous use of punctuation marks and compares boys and girls in terms of the use of punctuation marks. It mainly focused on finding out the proficiency of the students in the use of punctuation marks in English writing. In order to fulfill these objectives, 40 students of class XI (20 boys and 20 girls) from GVN Secondary schools of Banke District, Nepalgunj, Nepal were given test items related to the guided writing. To select school, the researcher used judgmental non-random sampling procedure and to choose students, random sampling procedures were used. The researcher found that full stop has the highest frequency (i.e. $34.42 \%$ ) and slash has the lowest frequency (i.e. 1.02\%) of the total use.
\end{abstract}

Keywords: proficiency, erroneous, punctuation marks, writing, mistake

\section{Introduction}

\subsection{General Background: Speech, Writing and Punctuation}

English is an international language and it is also known as the lingua franca because it works as a contact language among people from different speech communities. The major aspects of language are: speech and writing. They are two modes of communication through which we can perform our task in the different situations. Speech is oral form of language in which we can perform our task with the help of speech sounds and writing is the graphic form in which we can perform our task with the help of letters of the alphabet.

Speech and writing are the two modes of communication through which language can function in the society. Speech is oral form of making use of phonetic substance, i.e. speech sounds and writing is the graphic form making use of graphic substance, i.e. written symbols, like the letters of the alphabet. Speech may be considered the primary mode of communication in the sense that we speak before we can write.

Writing is one important medium of communication through which we can exchange our ideas, feelings, emotions and information from one person to another, one place to another. It makes the use of graphics i.e. written symbols like letters of alphabet. We can get freedom in writing to select subject matter, put our ideas, to organize those ideas in proper order and to provide clear reflection among the readers. Thus, to be a good writer we must think about the reader for whom we are writing, otherwise, it may not give any meaning or sense among the readers.

Writing itself is most complex skill of language among other skills. So, teaching writing to the second language learner is so challenging job for the teacher. There are numbers of different approaches, methods and techniques to the practice of writing skill both in and outside the classroom. Only a good teacher can choose an appropriate method of teaching and provide considerable amount of time for practice.

Punctuation is one of the important mechanics of writing. Simply speaking, punctuation refers to the use of standard marks and signs in writing to separate words into sentences, clauses, and phrases in order to clarify the meaning. e.g. Having been a teacher for fifty years, he felt perfectly relaxed among young people. Those marks or signs are called punctuation marks. Different scholars have defined punctuation in different ways. Such as: Carter and Carthy (2006, p. 838) say "punctuation exists in order to indicate the boundaries of grammatical units and to indicate grammatical information that is marked in spoken language by means of intonation, pitch, etc." In the same way, Hard et al. (1941, p. 
410) point out that "Punctuation marks are useful tools without which no writer could hope to convey his meaning to his reader with immediacy and accuracy."

Above mentioned definitions are given by different scholars in different occasions. They conclude that punctuation marks help to make the writing meaningful like supra-segmental features in speech help to make the meaning clear among the speakers.

\subsubsection{Importance and types of punctuation marks}

Punctuation marks writing clear, which direct the writer to express his ideas, feelings and information in certain ways? Punctuation plays a vital role in the written form of the message. If we are unable to use appropriate punctuation marks, it will mislead the reader while reading. Partridge (1953, p. 8) points out that "punctuation is not something that one applies as an ornament, for it is part of the structure".

Thus, a good writer chooses an appropriate punctuation mark to the sentence, clause, phrase and word which helps the writer to represent the flexibility of the human voice.

Allen (2002) gives following types of punctuation marks:

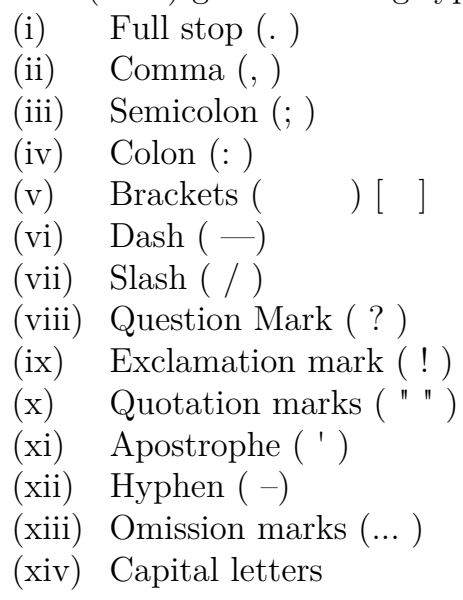

\subsubsection{Errors related to the punctuation}

Error analysis is a branch of applied linguistics which refers to the systematic study and analysis of the errors committed by the L2 learners. Sometimes learners can commit errors due to the minor reasons. These may contain slips of the tongue, slips of the pen, false starts, and changes of mind and so on. But sometimes they may commit errors due to incomplete knowledge of the target language.

In English punctuation plays a vital role to make the meaning clear among the readers. Inappropriate use of punctuation can mislead the reader while reading. To make our writing meaningful we have to use the punctuation marks properly. Thus error related to the punctuation is called the errors in the use of punctuation marks in written text.

Generally, learners make three types of punctuation errors. Such as, firstly, they may commit errors by leaving out the required punctuation mark to be used. It is also called omission of required punctuation mark. e.g. 'I'd love too but I have to go another place'. The correct form of this sentence is 'I'd love too but I have to go another place'. Secondly, they may commit error by using punctuation mark unnecessarily. In other words, they may use punctuation mark where it is not necessary Thirdly, they may commit error by using punctuation mark inappropriately. It is also called wrong use or they may use one punctuation instead of another e.g. 'I am fine and what about you.' The correct form of this sentence is 'I am fine and what about you?'

\subsection{Objectives of the Study}

The objectives of this research were as follows:

i) to find out the total use, correct use and erroneous use of punctuation marks.

ii) to compare boys and girls in terms of use and errors of punctuation marks

iii) to suggest some pedagogical implications. 


\subsection{Significance of the Study}

This research gives short introduction of all the punctuation marks that may be reference materials, for students, teachers and others. It points out the correct use; total use and erroneous use of punctuation marks which can be foundation for further study in this field. The findings and recommendations of this study will be fruitful for students teachers, textbook writers, syllabus designers and others who are involved in the English language teaching and learning.

\section{Review of the Related Literature}

Many research works have been carried out in the field of error analysis, specially related to the writing skill as well as grammatical items all around the world. But the attitude towards English language teaching and writing skill changes day by day. In the same way, nature of the errors and use of particular item or convention also changed according to the contemporary situation. Some of the researches carried out on error analysis specially related to the punctuation as well as grammatical items which are related to the present study are as follows:

Bhattarai (2001) carried out a research on 'the use of punctuation in free writing'. The objectives of his research work were to establish hierarchies of punctuation marks used in free writing, to establish hierarchies of errors on the use of punctuation marks, and to suggest some pedagogical implications. He used both primary and secondary sources for the collection of required data. He selected 120 students of twelfth grade for the study. The main research tool for the data collection was a questionnaire. After analysing and interpreting the data, he found that only eleven items of punctuation were found to be erroneously used.

Similarly, Khatri (2001) carried out a research on 'a study of errors in punctuation committed by xth graders'. His objectives of the study were: to identify the errors in the use of punctuation marks committed by 10th graders, to determine the frequency of errors, and to suggest some pedagogical implications. He used both primary and secondary sources of data collection. He selected 180 students of 10th grade of Dolakha district. He used subjective test as a major tool for data collection. He came to the conclusion that the students tended to commit more errors in the use of punctuation marks in free writing than in guided writing.

Ghimire (2005) carried out research on the 'Grey areas in English Grammar, Spelling and Punctuation'. His objectives of the study were: to determine grey area of grammar, spelling and punctuation in terms of sex, profession, age and nationality variables, to find out the frequency of occurrence of the alternate items in each grey area, and to suggest some pedagogical implications. He used both primary and secondary sources for data collection. He selected 58 native speakers of different nationalities in Kathmandu valley. A structured questionnaire was the main tool for data collection. He concluded that Nepalese students preferred the use of single to double inverted commas and inside full stop to outside full stop with inverted commas.

Many research works have been carried out on error analysis especially related to the writing skill but no study has been done to find out the proficiency of the secondary level students, especially Class XI on the use of punctuation marks. So, the present study is different from others in terms of objectives, class, and methodology, research tool, marking scheme, findings and recommendations.

\section{$3 \quad$ Methodology}

\subsection{Sources of Data}

The researcher used both primary and secondary sources of data to conduct this study. The primary source was used for collecting data and secondary sources were used to facilitate those data.

\subsubsection{Primary sources of data}

Primary sources of this study were 40 students of the Class XI from GVN Secondary schools of Banke district, Nepalgunj, Nepal.

\subsubsection{Secondary sources of data}


While carrying out this research, different books, journals, articles, theses and websites related to the present research were utilized as secondary sources of this study.

\subsection{Sample and Sampling Procedure}

The total sample of the study was 40 students of Class XI from GVN Secondary School, of Banke distric, Nepalgunj, Nepalt. The researcher applied both random and non-random sampling procedure to select required number of sample population. At last the researcher used fishbowl drawing technique to select $50 \%$ boys and $50 \%$ girls from the class.

\subsection{Tools for Data Collection}

Test item was the major tool for data collection. The researcher used the test item for written work (guided writing) as an essay.

\subsection{Limitations of the Study}

This study was limited to GVN Secondary School of Banke district, Nepalgunj, Nepal.. Only 40 students of class XI were the sample population, and out of 40, $50 \%$ were boys and $50 \%$ were girls. The test item was pre-determined and only total correct and erroneous use of punctuation marks was taken into account while checking the answer sheets. The following eleven punctuation marks were taken for the study:
a. Full stop (. )
b. Comma (, )
c. Colon $(:)$
d. Parenthesis ( )
e. Slash ( / )
f. Question Mark (?)
g. Exclamation mark (!)
h. Quotation mark ( " ")
i. Apostrophe ( ' $)$
j. Hyphen $(-)$
k. Capital letters

\section{$4 \quad$ Analysis and Interpretation}

\subsection{Analysis of Total Punctuation Marks}

Table 1. Analysis of total punctuation marks

\begin{tabular}{cll}
\hline S.N. & Items of Punctuation & percentage \\
\hline 1. & Full stop & 34.42 \\
2. & Comma & 15.19 \\
3. & Apostrophe & 20.17 \\
4. & Question mark & 7.2 \\
5. & Quotation Mark & 4.83 \\
6. & Slash & 1.2 \\
7. & Parenthesis & 1.19 \\
8. & Exclamation Mark & 3.51 \\
9. & Colon & 3.17 \\
10. & Capitalization & 7.34 \\
11. & Hyphen & 1.23 \\
\hline \multicolumn{3}{c}{ Total } \\
\hline
\end{tabular}


Here the researcher deals the analysis and interpretation of all the punctuation marks used by the total informants. In other words, the total frequency of each individual punctuation marks (i.e. full stop, comma, etc.) used by the 40 students of class XI. The total number refers to the correct and erroneous use of punctuation marks. To find out the total number of punctuation marks, the following formula was used: Total use of punctuation marks $=$ Correct use + Erroneous use of punctuation marks. This is presented with the help of Table 1 .

The above table shows $34.42 \%$ full stop, $15.91 \%$ commas, $20.17 \%$ apostrophe, $7.12 \%$ question marks, $4.43 \%$ quotation marks, $1.02 \%$ slashes, $1.19 \%$ parentheses, $3.51 \%$ exclamation marks, $3.17 \%$ colons, $7.43 \%$ capital letters and $1.23 \%$ hyphens were totally used by the total informants.

Thus, the highest number of full stop and the lowest number of slashes were used. In between them, apostrophe, comma, capital letters, question mark, quotation mark, exclamation mark, colon, hyphen and parenthesis were found in the second third, fourth and so on respectively.

\subsection{Itemwise Analysis of Punctuations}

This section deals with the item wise analysis and interpretation of punctuation used by the students.

\subsubsection{Full stop}

Table 2. Correct, erroneous and total used full stops

\begin{tabular}{ccccc}
\hline S.N. & Sex & Correct $\%$ & Erroneous $\%$ & Total $\%$ \\
\hline 1. & Male & 9.94 & 8.23 & 17.82 \\
2. & Female & 7.47 & 9.13 & 16.59 \\
\hline
\end{tabular}

The above table shows that in the use of full stop, $6.54 \%$ were correctly used, $8.28 \%$ were erroneously and $17.82 \%$ were totally used by the male students. Similarly, $7.47 \%$ were correctly used, $9.13 \%$ were erroneously used and $16.59 \%$ were totally used by the female students.

\subsubsection{Comma}

Table 3. Correct, erroneous and total used commas

\begin{tabular}{ccccc}
\hline S.N. & Sex & Correct $\%$ & Erroneous $\%$ & Total $\%$ \\
\hline 1. & Male & 1.60 & 6.12 & 7.72 \\
2. & Female & 1.41 & 6.77 & 8.18 \\
\hline
\end{tabular}

The above table shows that in the use of comma, $1.60 \%$ were correctly used, $6.12 \%$ were erroneously and $7.72 \%$ were totally used by the male students. Similarly, $1.41 \%$ were correctly used, $6.77 \%$ were erroneously used and $8.18 \%$ were totally used by the female students.

\subsubsection{Apostrophe}

Table 4. Correct, erroneous and total used apostrophes

\begin{tabular}{ccccc}
\hline S.N. & Sex & Correct $\%$ & Erroneous $\%$ & Total\% \\
\hline 1. & Male & 6.16 & 4.31 & 10.47 \\
2. & Female & 3.63 & 6.07 & 9.7 \\
\hline
\end{tabular}

The above table shows that in the use of apostrophe, $6.16 \%$ were correctly used, $4.3 \%$ were erroneously and $10.47 \%$ were totally used by the male students. Similarly, $3.63 \%$ were correctly used, $6.07 \%$ were erroneously used and $9.70 \%$ were totally used by the female students.

\subsubsection{Question mark}

Table 5 shows that in the use of question mark, $1.55 \%$ were correctly used, $1.99 \%$ were erroneously 
and $3.54 \%$ were totally used by the male students. Similarly, $1.30 \%$ were correctly used, $2.28 \%$ were erroneously used and $3.38 \%$ were totally used by the female students.

Table 5. Correct, erroneous and total used question marks

\begin{tabular}{ccccc}
\hline S.N. & Sex & Correct $\%$ & Erroneous $\%$ & Total $\%$ \\
\hline 1. & Male & 1.55 & 1.99 & 3.54 \\
2. & Female & 1.30 & 2.28 & 3.38 \\
\hline
\end{tabular}

\subsubsection{Quotation mark}

Table 6. Correct, erroneous and total used quotation marks

\begin{tabular}{ccccc}
\hline S.N. & Sex & Correct $\%$ & Erroneous\% & Total\% \\
\hline 1. & Male & 0.44 & 2.00 & 2.44 \\
2. & Female & 0.36 & 2.02 & 2.38 \\
\hline
\end{tabular}

The above table shows that in the use of quotation mark, $0.44 \%$ were correctly used, $2.00 \%$ were erroneously and $2.44 \%$ were totally used by the male students. Similarly, $0.36 \%$ were correctly used, $2.02 \%$ were erroneously used and $2.38 \%$ were totally used by the female students.

\subsubsection{Slash}

Table 7. Correct, erroneous and total used slashes

\begin{tabular}{ccccc}
\hline S.N. & Sex & Correct $\%$ & Erroneous $\%$ & Total\% \\
\hline 1. & Male & 0.10 & 0.43 & 0.53 \\
2. & Female & 0.06 & 0.41 & 0.47 \\
\hline
\end{tabular}

The above table shows that in the use of slash, $0.10 \%$ were correctly used, $0.43 \%$ were erroneously and $0.53 \%$ were totally used by the male students. Similarly, $0.06 \%$ were correctly used, $0.41 \%$ were erroneously used and $0.47 \%$ were totally used by the female students.

\subsubsection{Parenthesis}

Table 8. Correct, erroneous and total used parentheses

\begin{tabular}{ccccc}
\hline S.N. & Sex & Correct $\%$ & Erroneous $\%$ & Total\% \\
\hline 1. & Male & 0.04 & 0.53 & 0.57 \\
2. & Female & 0.05 & 0.52 & 0.57 \\
\hline
\end{tabular}

The above table shows that in the use of parenthesis, $0.04 \%$ were correctly used, $0.53 \%$ were erroneously and $0.57 \%$ were totally used by the male students. Similarly, $0.05 \%$ were correctly used, $0.52 \%$ were erroneously used and $0.57 \%$ were totally used by the female students.

\subsubsection{Exclamation mark}

Table 9. Correct, erroneous and total used exclamation marks

\begin{tabular}{ccccc}
\hline S.N. & Sex & Correct $\%$ & Erroneous $\%$ & Total\% \\
\hline 1. & Male & 0.03 & 1.59 & 1.89 \\
2. & Female & 0.28 & 1.31 & 1.59 \\
\hline
\end{tabular}

The above table shows that in the use of exclamation mark, $0.30 \%$ were correctly used, $1.59 \%$ were erroneously and $1.89 \%$ were totally used by the male students. Similarly, $0.28 \%$ were correctly used, 
$1.31 \%$ were erroneously used and $1.59 \%$ were totally used by the female students.

\subsubsection{Colon}

Table 10. Correct, erroneous and total used colons

\begin{tabular}{ccccc}
\hline S.N. & Sex & Correct $\%$ & Erroneous $\%$ & Total\% \\
\hline 1. & Male & 0.51 & 0.06 & 1.57 \\
2. & Female & 0.28 & 3.13 & 1.59 \\
\hline
\end{tabular}

The above table shows that in the use of colon, $0.51 \%$ were correctly used, $1.06 \%$ were erroneously and $1.57 \%$ were totally used by the male students. Similarly, $0.28 \%$ were correctly used, $1.31 \%$ were erroneously used and $1.59 \%$ were totally used by the female students.

\subsubsection{Capitalization}

Table 11. Correct, erroneous and total used capitalization

\begin{tabular}{ccccc}
\hline S.N. & Sex & Correct $\%$ & Erroneous $\%$ & Total $\%$ \\
\hline 1. & Male & 2.71 & 1.19 & 3.90 \\
2. & Female & 2.43 & 1.08 & 3.51 \\
\hline
\end{tabular}

The above table shows that in the use of capital letters, $2.71 \%$ were correctly used, $1.19 \%$ were erroneously and $3.90 \%$ were totally used by the male students. Similarly, $2.43 \%$ were correctly used, $1.08 \%$ were erroneously used and $3.51 \%$ were totally used by the female students.

\subsubsection{Hyphen}

Table 12. Correct, erroneous and total used hyphens

\begin{tabular}{ccccc}
\hline S.N. & Sex & Correct $\%$ & Erroneous $\%$ & Total $\%$ \\
\hline 1. & Male & 0.09 & 0.57 & 0.66 \\
2. & Female & 0.04 & 0.52 & 0.56 \\
\hline
\end{tabular}

The above table shows that in the use of hyphen, $0.09 \%$ were correctly used, $0.57 \%$ were erroneously and $0.66 \%$ were totally used by the male students. Similarly, $0.04 \%$ were correctly used, $0.52 \%$ were erroneously used and $0.56 \%$ were totally used by the female students.

\subsubsection{Comparison between male and female in terms of correctly used punctuation marks}

Table 13. Comparison between male and female in terms of correctly used punctuation marks

\begin{tabular}{clcc}
\hline S.N. & Items of Punctuation & Male $(\%)$ & Female $(\%)$ \\
\hline 1. & Full stop & 23.61 & 18.49 \\
2. & Comma & 3.95 & 3.49 \\
3. & Apostrophe & 15.23 & 8.98 \\
4. & Question Mark & 3.82 & 3.22 \\
5. & Quotation Mark & 1.90 & 0.89 \\
6. & Slash & 0.26 & 0.16 \\
7. & Parenthesis & 0.09 & 0.13 \\
8. & Exclamation Mark & 0.26 & 0.69 \\
9. & Colon & 1.26 & 0.69 \\
10. & Capitalization & 6.21 & 6.02 \\
11. & Hyphen & 0.23 & 0.09 \\
\hline & Total & 57.01 & 42.88 \\
\hline
\end{tabular}


This sub-section deals with the comparison between male and female students in terms of correctly used punctuation marks. This is presented with the help of the Table 13.

The table shows the comparison between male and female students in terms of correctly used punctuation marks.

About twenty four percent full stop, 3.95\% comma, 15.23\% apostrophe, $3.82 \%$ question mark, $1.09 \%$ quotation mark, $0.26 \%$ slash, $0.09 \%$ parenthesis, $0.76 \%$ exclamation mark, $1.26 \%$ colon, $6.71 \%$ capital letters and $0.23 \%$ hyphen were correctly used by the male students.

In the same way, $18.49 \%$ full stop, $3.49 \%$ comma, $8.98 \%$ apostrophe, $3.22 \%$ question mark, $0.89 \%$ quotation mark, $0.16 \%$ slash, $0.13 \%$ parenthesis, $0.69 \%$ exclamation mark, $0.69 \%$ colon, $6.02 \%$ capitalization and $0.09 \%$ hyphen were correctly used by the female students.

Thus, male students used $5.12 \%$ full stop, $0.46 \%$ comma, $6.25 \%$ apostrophe, $0.6 \%$ question mark, $0.2 \%$ quotation mark, $0.1 \%$ slash, $0.07 \%$ exclamation mark, $0.527 \%$ colon, $0.69 \%$ capitalization and $0.14 \%$ hyphen more correctly than the female students. In the same way, female students used $0.04 \%$ parenthesis more correctly than the male students.

\subsubsection{Comparison between male and female students in terms of totally used punctuation marks}

Table 14. Comparison between male and female students in terms of totally used punctuation marks

\begin{tabular}{clcc}
\hline S.N. & Items of Punctuation & Male (\%) & Female (\%) \\
\hline 1. & Full stop & 17.82 & 16.59 \\
2. & Comma & 7.73 & 8.18 \\
3. & Apostrophe & 10.47 & 9.70 \\
4. & Question Mark & 3.53 & 3.58 \\
5. & Quotation Mark & 2.45 & 2.39 \\
6. & Slash & 0.54 & 0.48 \\
7. & Parenthesis & 0.58 & 0.58 \\
8. & Exclamation Mark & 1.91 & 1.59 \\
9. & Colon & 1.57 & 1.59 \\
10. & Capitalization & 3.91 & 3.52 \\
11. & Hyphen & 0.67 & 0.56 \\
\hline & Total & 51.48 & 48.76 \\
\hline
\end{tabular}

The above table shows the comparison between male and female students in terms of totally used punctuation marks. About eighteen percent full stop, $7.73 \%$ comma, 10.47\% apostrophe, 35.5\% question mark, $2.45 \%$ quotation mark, $0.54 \%$ slash, $0.58 \%$ parenthesis, $1.9 \%$ exclamation mark, $1.57 \%$ colon, $3.9 \%$ capitalization and $0.67 \%$ hyphen were totally used by male students. In the same way, $16.59 \%$ full stop, $8.18 \%$ comma, $9.70 \%$ apostrophe, $3.58 \%$ question mark, $2.39 \%$ quotation mark, $0.48 \%$ slash, $0.58 \%$ parenthesis, $1.59 \%$ exclamation mark, $1.59 \%$ colon, $3.52 \%$ capitalization and $0.56 \%$ hyphen were toally used by the female students.

Thus, in terms of totality, male students used $1.23 \%$ full stop, $0.77 \%$ apostrophe, $0.06 \%$ question mark, $0.06 \%$ slash, $0.32 \%$ exclamation mark, $0.39 \%$ capitalization and $\quad 0.11 \%$ hyphen more than the female students. In the same way, male students used $0.45 \%$ comma, $0.05 \%$ question mark, and $0.02 \%$ colon less than female students but in the case of parenthesis, both male and female students used equal number.

\section{$5 \quad$ Conclusions and Recommendations}

The data collected from the students were analyzed, interpreted and compared in this study. So, the major conclusion and recommendations of the study are as follow:

\subsection{Conclusions}

From the analysis and interpretation of data the following conclusions have been drawn: 
i. Among eleven punctuation marks, the researcher found that full stop has the highest frequency (i.e. $34.42 \%$ of the total use) and slash has the lowest frequency (i.e. $1.02 \%$ of the total use).

ii. The total frequency of the correct use of punctuation marks was $40.40 \%$ of the total use.

iii. The total frequency of the erroneous use of punctuation marks was was $59.59 \%$ of the total use.

iv. The frequency of the total punctuation marks used by the male students was found $51.78 \%$ of the total use.

v. The frequency of the total punctuation marks used by the female students was found $48.76 \%$ of the total use.

vi. Male students used $23.06 \%$ punctuation marks correctly whereas female students used $17.33 \%$ correctly. Thus, male students were found more proficient than female students.

\subsection{Recommendations}

i. Girls are found less proficient in the use of punctuation marks appropriately than male students. So, they need more encouragement and help to develop writing skill as well as punctuation marks.

ii. Punctuation marks should be taught along with other skills. e.g. while teaching reading passages, the teacher should make the students aware about the use of punctuation marks.

iii. Punctuation marks should be prescribed as a separate course while designing the language syllabus.

iv. To get the perfect mastery over punctuation marks as well as other mechanics of writing, writing skill should be given more priority in language syllabus.

v. Only $40.40 \%$ punctuation marks were correctly used by the students. Thus, to increase the proficiency level of the students, the teacher should provide sufficient amount of time to practice writing activities in the ELT classroom.

vi. The syllabus designers as well as textbook writers should include appropriate exercises on the use of punctuation marks.

vii. Punctuation marks should be taught from elementary level. So, that it helps to develop writing skill in the proper way.

\section{References}

1. Allen, R. (2002). Punctuation. London: Oxford University Press.

2. Bhattarai, Y.B. (2001). "A study on the use of punctuation in free writing". An unpublished M.Ed. thesi, T.U., Kirtipur.

3. Carter, R. and McCarthy, M. (2006). Cambridge grammar of English. London: CUP.

4. Ghimire, R.N. (2005). "Grey area in English grammar spelling and punctuation: A descriptive study". An unpublished M.Ed. thesis. T.U., Kirtipur.

5. Gordon, I. (1978). Practical punctuation. London: Heinemann Educational Books.

6. Hard, F. et al. (1941). Writing and reading English propose. New York: Farrar and Rinehart, Inc.

7. Khatri, L.B. (2001). "A study of errors in punctuation committed by the graders". An unpublished M.Ed. thesis. T.U., Kirtipur. 